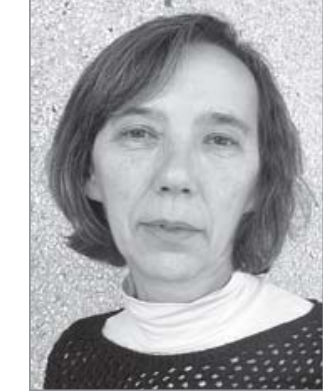

Т. В. Майдль

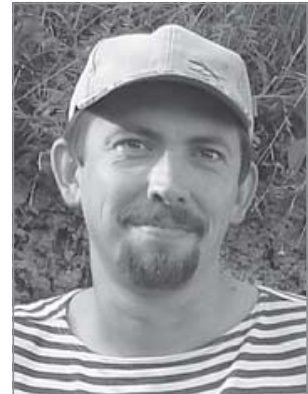

П. А. Безносов

Институт геологии Коми НЦ УрО РАН, Сыктывкар maydl@geo.komisc.ru; beznosov@geo.komisc.ru

Приводятся изотопная характеристика типового разреза сосногорской и ижемской свит Южного Тимана, а также данные по распределению стронция. Обсуждаются условия формирования этих отложений.

Ключевые слова: изотопия, углерод, кислород, стронций, девон.

\title{
CARBON AND OXYGEN ISOTOPE COMPOSITION AND THE DISTRIBUTION OF STRONTIUM IN THE LOWER FAMENNIAN SECTION OF IZHMA RIVER [SOUTH TIMAN]
}

\author{
T. V. Maydl, P. A. Beznosov
}

The isotopic characteristic and data on the strontium distribution in the type section of the Sosnogorsk and Izhma Formations are given. The sedimentological environments of these deposits are discussed.

Keywords: isotopy, carbon, oxygen, strontium, Devonian.

Наиболее полный разрез нижнего фамена на Южном Тимане вскрывается в обн. 20 по реке Ижма (геологический памятник природы «Сосновский»). Этот разрез является типовым для двух свит - сосногорской и ижемской. Сосногорская свита представлена толщей переслаивания глинистых и доломитистых известняков, известковистых доломитов и глин. Ее отложения сформировались в мелководных, предположительно лагунных условиях [1]. Относительная изоляция данной части бассейна, вызванная выведением на поверхность расположенного восточнее тела позднефранского барьерного рифа [3, 12], определила крайнюю обедненность отложений сосногорской свиты органогенными остатками. Лишь слой 40 (здесь и далее нумерация слоев дана по П. А. Безносову и др. [2]), известный под названием «рыбный доломит», содержит многочисленные хорошо сохранившиеся макроостатки эндемичного сообщества позвоночных. Этот слой, представленный доломитистым известняком с обильными кальцитизированными оогониями и инкрустациями харовых водорослей и глинистым темпеститом в основании, по всей видимости, сформировался в результате одного или нескольких близких по времени штормовых событий. По комплексу миоспор и остракодам сосногорская свита коррелируется с волгоградским горизонтом Центрального девонского поля (ЦДП) [3, 4]. Видимая в обнажении мощность сосногорской свиты составляет $11 \mathrm{M}$, полная мощность по данным скважины - около 30 м.

Выше трансгрессивно с размывом залегают мелководно-морские открыто-шельфовые отложения ижемской свиты, представленные неравномерно-глинистыми узловатыми известняками с прослоями однородных, плитчатых и биокластовых известняков и глин и охарактеризованные обильной фауной беспозвоночных задонского возраста. Видимая в обнажении мощность ижемской свиты составляет $20 \mathrm{M}$.

Особый интерес к данному разрезу связан с недавним обнаружением в слое «рыбного доломита» частично сочлененных остатков новой, еще не описанной формы примитивного тетрапода. Эта форма как стратиграфически, так и морфологически является наиболее древней и рыбообразной среди других девонских тетрапод, известных по относительно полным скелетам [7]. Превращение рыбьего плавника в конечность с пальцами и появление первых тетрапод в девоне стало ключевым моментом в эволюции позвоночных животных, обеспечившим им в дальнейшем выход на сушу. В этой связи реконструкция условий обитания и выявление возможных причин гибели этого уникального сообщества имеет крайне важное значение. С этой целью нами был про- 
веден изотопно-геохимический анализ карбонатных отложений данного разреза.

Измерения содержаний стабильных изотопов углерода и кислорода выполнены в Институте геологии Коми НЦ УрО РАН на масс-спектрометре «DELTA VAdvantage» (аналитик И. В. Смолева). Значения $\delta^{13} \mathrm{C}_{\text {карб }}$ даны в промилле относительно стандарта $\mathrm{PDB}$, а $\delta^{18} \mathrm{O}_{\text {карб }}-$ относительно стандарта SMOW. Ошибка определения $\delta^{13} \mathrm{C}$ и $\delta^{18} \mathrm{O}_{\text {карб }}$ не превышает 0.04 и $0.06 \%$ соответственно. Содержание стронция определялось методом эмиссионного спектрального анализа (аналитики Т. В. Якимова, Р. С. Арасланова). Погрешность метода 12 $15 \%$. Результаты анализов приведены в таблице и на рисунке.

В первой пачке сосногорской свиты величины изотопного уплотнения $\delta^{13} \mathrm{C}_{\text {карб }}$ и $\delta^{18} \mathrm{O}_{\text {карб }}$ известняков составляют -3.1 и $23.7 \%$ о соответственно. Кривые изменения величин $\delta^{13} \mathrm{C}_{\text {карб }}$ и $\delta^{18} \mathrm{O}_{\text {карб }}$ в нижней, литологически наиболее мелководной части второй пачки демонстрируют смещение, отрицательное по углероду (до $-3.8 \%$ ) и положительное по кислороду (до $26.1 \%$ ). В верхней, большей ее части отмечается утяжеление как углерода, так и кислорода, происходящее практически синхронно. Положительный экскурс изотопных кривых соответствует и третьей пачке. Достигнув максимальных значений вблизи кровли слоя 41 микробиальных доломитов, значения $\delta^{13} \mathrm{C}_{\text {карб }}$ $\delta^{18} \mathrm{O}_{\text {карб }}$ начинают убывать. Эта тенденция наблюдается и в четвертой пачке. В вышележащих мелководноморских отложениях ижемской свиты значения $\delta^{13} \mathrm{C}_{\text {карб }}$ достигают средних для разреза значений (около $-1 \%$ ) и далее почти не меняются. Кривая

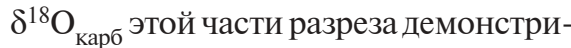
рует значительное сходство с кривой

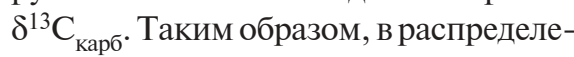
нии изотопов углерода и кислорода отмечается прямая корреляционная связь.

В нижнефаменском разрезе на Южном Тимане обнаруживается ряд особенностей в изотопных характеристиках углерода и кислорода по сравнению с одновозрастными разрезами в других регионах мира. Максимальные значения $\delta^{13} \mathrm{C}_{\text {карб }}$ в них достигают 2.5-3, а в отдельных случаях и $4 \%$ $[11,13]$, тогда как изученный нами разрез отличается более низкими значениями этого показателя - не более $2.1 \%$. Величина абсолютных значе- ний $\delta^{13} \mathrm{C}_{\text {карб }}$ может меняться в зависимости от батиметрических, широтных и прочих факторов, варьируя в пределах 1-1.5\% и более, однако считается, что амплитуда изотопного сдвига при этом должна оставаться постоянной [8]. Согласно палеогеографическим реконструкциям тиманский разрез, как и большинство других, описанных в литературе, располагался в приэкваториальном поясе. Общая амплитуда изотопно-углеродного сдвига составляет в нем 5 \%о, что в полтора-два раза больше, чем в разрезах других регионов мира, где этот показатель не превышает 2.5-3 \%о [13]. Величина абсолютных значений изотопного сдвига напрямую связана с низкими значениями $\delta^{13} \mathrm{C}_{\text {карб }}$ в основании разреза, где они достигают $-3.8 \%$. Учитывая крайнюю мелководность отложений с самыми низкими негативными значениями $\delta^{13} \mathrm{C}_{\text {карб }}$, логично предположить влияние на их формирование подтока пресных вод с континента, обогащенных изотопно-облегченным почвенным бикарбонатом.

Синхронно с увеличением значений $\delta^{13} \mathrm{C}_{\text {карб }}$ в разрезе сосногорской свиты наблюдается постепенное возрастание значений $\delta^{18} \mathrm{O}_{\text {карб. }}$. То же отмечено в одновозрастных разрезах и в других регионах мира $[14,20]$. Однако абсолютные значения $\delta^{18} \mathrm{O}_{\text {карб }}$ в изученном нами разрезе в среднем на $1-1.5 \%$ ниже, чем в иных низкоширотных разрезах $[14,21]$. Одним из факторов, обуславливающих низкие содержания $\delta^{18} \mathrm{O}_{\text {карб }}$ в карбонатных породах, является поступление изотопно-легких вод с речным стоком. Наиболее ярко это выражается в эпиконтинентальных морях, в которых отличие от средних океанических значений достигает 1-2\%o [15]. Так как в позднедевонское время район Южного Тимана находился в приэкваториальных широтах, наблюдаемое понижение значений $\delta^{18} \mathrm{O}_{\text {карб}}$, очевидно, было связано с разбавлением изначально морских вод бассейна изотопно-легкими пресными континентальными водами.

Кратковременные резкие утяжеления изотопного состава карбонатного углерода, или позитивные максимумы величины $\delta^{13} \mathrm{C}_{\text {карб }}$, в пограничных франско-фаменских разрезах принято связывать с кратковременными трансгрессиями. Они обусловили не только аноксию отдельных акваторий, но и дополнительное поступление с суши фосфора, а следовательно, и усиленную фоссилизацию изотопно-легкого $\mathrm{C}_{\text {орг }}$ с соответствующим обогащением морской воды изотопом ${ }^{13} \mathrm{C}$ [9]. Положительный экскурс в изменении величины $\delta^{13} \mathrm{C}_{\text {карб }}$ в изучаемом разрезе завершается максимумом в пласте доломита, перекрывающем костеносный слой. С этим же рубежом совпадает смена ассоциаций макро- и микрофитов: от ассоциации гидрологически открытого мезотрофного бассейна (преобладание харофитов) к ассоциации закрытого эвтрофного водоема (микробиальное сообщество).

Кроме того, повышение содержания $\delta^{13} \mathrm{C}_{\text {карб }}$ в III пачке сосногорской свиты могло быть связано с процессом метаногенерации в осадке. Как известно, метан при своем формировании забирает из среды повышенную долю ${ }^{12} \mathrm{C}$, что приводит к осаждению карбоната с утяжеленным изотопным составом углерода [6]. В слоях 40 и 41 наблюдаются многочисленные вертикальные трубкообразные полости диаметром около $0.3-0.5$ см. По ряду признаков эти текстуры не могут быть отнесены к ихнофоссилиям и трактуются нами как следы выхода газов. Очевидно, что первичный осадок слоя 40 содержал большое количество органического вещества, представленного талломами харовых водорослей и трупами позвоночных. Быстрое погребение в результате штормового процесса способствовало разложению его в дизоксидных условиях с образованием метана, что в конечном счете также должно было привести к сдвигу величины $\delta^{13} \mathrm{C}_{\text {карб }}{ }^{\mathrm{B}}$ положительную сторону.

Положительный экскурс величины $\delta^{18} \mathrm{O}_{\text {карб }}$ определяется как температурой воды, так и её соленостью. Практически синхронное повышение значений $\delta^{13} \mathrm{C}_{\text {карб }}$ и $\delta^{18} \mathrm{O}_{\text {карб, }}$, наблюдаемое и в нашем разрезе, большинством исследователей трактуется как свидетельство похолодания климата. Так, отмеченные в разрезах пограничных франско-фаменских отложений Германии положительные аномалии $\delta^{18} \mathrm{O}_{\text {карб }}$ с максимальной амплитудой $1-1.5 \%$, параллельные положительным экскурсам $\delta^{13} \mathrm{C}_{\text {карб}}$, трактуются как результат охлаждения поверхностных вод в низких широтах на $5-7{ }^{\circ} \mathrm{C}$ вследствие понижения концентрации углекислого газа в атмосфере [14]. Расчетное падение глобальных температур в раннем фамене по сравнению с поздним франом составляет $4.4{ }^{\circ} \mathrm{C}$ около полюсов и $2.1^{\circ} \mathrm{C}$ на экваторе [9]. В нашем разрезе изменение величины $\delta^{18} \mathrm{O}_{\text {карб }}$ в слое 41 может быть свиде- 
тельством увеличения солености бассейна при уменьшении его глубины и выпаривании либо в результате притока соленых «океанских вод» при трансгрессии.

Таким образом, наблюдаемые здесь отличия от известных одновозрастных разрезов морского генезиса как по углероду, так и по кислороду обусловлены, вероятно, экранированием и обособлением этой части бассейна. Связь с океаном, возможно, возобновлялась при кратковременных мелкомасштабных трансгрессиях, влияние которых постепенно нарастало вверх по разрезу сосногорской свиты. Во время накопления четвертой ее пачки изоляция была преодолена и связь с остальной частью бассейна восстановлена.

То же подтверждается данными по содержанию стронция в изученном разрезе. Содержание стронция в карбонатных породах либо его соотношение с содержанием кальция может использоваться в качестве показателя солености бассейна [18, 19]. Прибрежные

Изотопный состав карбонатного углерода и кислорода

и геохимическая характеристика карбонатных пород нижнефаменского разреза по р. Ижма (обн. 20)

\begin{tabular}{|c|c|c|c|c|c|c|c|c|c|}
\hline \multicolumn{2}{|c|}{ Hoмep } & $\delta^{13} \mathrm{C}_{\mathrm{\kappa an}}$ & $\delta^{18} \mathrm{O}_{\text {кар }}$ & $\mathrm{Sr}$ & $\mathrm{CaO}$ & $\mathrm{MgO}$ & $\mathrm{CO}_{2}$ & II. 0. & $\mathrm{P}_{2} \mathrm{O}_{5}$ \\
\hline пробы & слоя & $\%(\mathrm{PDB})$ & $\%(\mathrm{SMOW})$ & $\Gamma / T$ & \multicolumn{5}{|c|}{$\%$} \\
\hline 56 & 81 & -0.3 & 24.3 & 430 & 50.95 & 0.66 & 38.78 & 4.63 & 0.017 \\
\hline 55 & 80 & -1.0 & 23.4 & 360 & 49.14 & 1.01 & 38.38 & 6.61 & 0.008 \\
\hline 53 & 78 & -1.6 & 22.4 & 420 & 49.19 & 0.85 & 38.66 & 9.5 & 0.038 \\
\hline 52 & 77 & -0.8 & 24.4 & 380 & 49.59 & 1.18 & 39.41 & 5.83 & 0.015 \\
\hline 51 & 76 & -0.04 & 23.8 & 420 & 48.99 & 1.95 & - & - & - \\
\hline 49 & 74 & -0.4 & 24.2 & 370 & 48.59 & 2.2 & - & - & - \\
\hline 48 & 73 & -1.2 & 23.6 & 480 & 51.24 & 3.52 & - & - & - \\
\hline 47 & 71 & -0.1 & 25.2 & 350 & 48.99 & 0.85 & 38.84 & 8.1 & 0.009 \\
\hline 46 & 70 & -0.6 & 23.2 & 410 & 49.38 & 1.58 & - & - & - \\
\hline 45 & 68 & -0.9 & 23.4 & 410 & 47.05 & 1.44 & - & - & - \\
\hline 44 & 67 & -0.9 & 23.4 & 400 & 51.65 & 2.3 & - & - & - \\
\hline 43 & 65 & -0.6 & 24.3 & 330 & 43.55 & 1.67 & - & - & - \\
\hline 42 & 64 & -0.5 & 24.1 & 360 & 45.66 & 1.35 & 36.20 & - & 0.074 \\
\hline 40 & 61 & -0.4 & 24.0 & 380 & 50.13 & 2.55 & - & & - \\
\hline 39 & 59 & -0.8 & 23.8 & 360 & 49.54 & 1.78 & 41.08 & 5.55 & 0.029 \\
\hline 38 & 57 & -0.6 & 24.3 & 320 & 38.03 & 4.28 & - & - & - \\
\hline 37 & 54 & -1.6 & 24.4 & 330 & 47.03 & 1.34 & 38.42 & 8.61 & 0.024 \\
\hline 36 & 53 & -1.4 & 24.9 & 300 & 42.51 & 1.3 & - & - & - \\
\hline 35 & 52 & -2.0 & 23.6 & 290 & 44.19 & 1.98 & - & - & - \\
\hline 34 & 51 & -1.8 & 25.7 & 390 & 45.51 & 1.09 & - & - & - \\
\hline 33 & 50 & -2.7 & 24.7 & 360 & 47.44 & 1.66 & - & - & - \\
\hline 32 & 50 & -2.5 & 24.6 & 410 & 42.97 & 2.84 & - & - & - \\
\hline 31 & 50 & -1.8 & 23.9 & 390 & 47.31 & 0.96 & 35.01 & 9.8 & 0.81 \\
\hline 30 & 48 & -4.3 & 24.8 & 320 & 40.89 & 1.52 & - & - & - \\
\hline 29 & 45 & -2.4 & 25.6 & 390 & 46.25 & 0.86 & 35.58 & - & 0.074 \\
\hline 28 & 43 & -1.8 & 24.2 & 240 & 41.55 & 1.1 & - & - & - \\
\hline 27 & 41 & 0.6 & 26.8 & 720 & 30.24 & 15.45 & 41.82 & 8.87 & \\
\hline 26 & 41 & 2.1 & 29.2 & 1100 & 29.28 & 17.5 & 42.03 & 5.83 & - \\
\hline 23 & 41 & -0.4 & 25.2 & 460 & 29.24 & 15.43 & 40.65 & 8.96 & - \\
\hline 22 & 41 & 1.8 & 25.0 & 460 & 27.59 & 15.83 & 38.45 & 12.86 & - \\
\hline 21 & 41 & 1.1 & 25.2 & 520 & 29.43 & 14.79 & 39.29 & 12.67 & - \\
\hline 20 & 40 & -0.7 & 25.4 & 500 & 38.42 & 11.46 & 42.67 & 3.3 & - \\
\hline 19 & 40 & -0.8 & 23.4 & 410 & 45.85 & 4.95 & 39.95 & 3.43 & - \\
\hline 18 & 40 & -0.9 & 23.7 & 790 & 43.21 & 6.38 & 40.80 & 4.68 & - \\
\hline 17 & 40 & -0.1 & 24.3 & 450 & 40.33 & 10.35 & 42.47 & 3.2 & 0.092 \\
\hline 16 & 40 & -1.3 & 23.6 & 570 & 46.33 & 4.09 & 40.46 & 4.51 & - \\
\hline 15 & 37 & -1.4 & 23.4 & 410 & 50.96 & 0.58 & 38.93 & 5.6 & 0.15 \\
\hline 14 & 35 & -1.5 & 24.4 & 380 & 41.75 & 1.84 & - & - & - \\
\hline 13 & 34 & -1.0 & 24.9 & 300 & 19.04 & 3.39 & - & - & - \\
\hline 12 & 32 & -1.8 & 25.6 & 250 & 36.7 & 2.73 & - & - & - \\
\hline 11 & 30 & -2.3 & 24.7 & 240 & 36.44 & 3.01 & - & - & - \\
\hline 10 & 26 & -2.2 & 24.7 & 230 & 36.27 & 1.94 & - & - & - \\
\hline 09 & 23 & -3 & 26.6 & 270 & 30.08 & 17.56 & 42.25 & 5.9 & 0.022 \\
\hline 08 & 21 & -1.7 & 24.5 & 280 & 40.54 & 1.73 & - & - & - \\
\hline 07 & 15 & -2.6 & 23.4 & 250 & 33.5 & 2.17 & - & - & - \\
\hline 06 & 13 & -3.4 & 26 & 250 & 27.56 & 19.19 & - & - & - \\
\hline 05 & 11 & -3.8 & 26.1 & 250 & 32.68 & 12.64 & 37.61 & 8.41 & - \\
\hline 04 & 9 & -3.4 & 25.7 & 290 & 29.01 & 13.57 & 37.88 & 14.72 & 0.041 \\
\hline 03 & 7 & -3.3 & 21.8 & 240 & 40.11 & 4.09 & - & - & - \\
\hline 02 & 5 & -3.2 & 24 & 280 & 43.89 & 1.78 & 34.61 & - & 0.044 \\
\hline 01 & 4 & -3.1 & 23.7 & 300 & 49.38 & 1.88 & - & - & - \\
\hline
\end{tabular}

Примечание. Породообразующие компоненты определялись методом химического анализа. Н. о. - нерастворимый остаток. Данные, набранные курсивом, - результаты приближенно-количественного рентгенофлуоресцентного анализа. Прочерк - не определялось. 
отложения с пониженной соленостью отличаются и более низким содержанием Sr. Карбонаты, осаждающиеся из вод повышенной солености, напротив, обогащаются этим элементом. Так, например, в известняках и доломитах эвапоритовых фаций его содержание составляет не менее $0.1 \%$ [5]. Временной тренд распределения стронция в карбонатных породах тиманского разреза демонстрирует значительное сходство с трендами изотопного уплотне- ния как $\delta^{13} \mathrm{C}_{\text {карб }}$, так и $\delta^{18} \mathrm{O}_{\text {карб }}$ (см. рисунок). Примечательно, что кларковые содержания $\mathrm{Sr}(0.03-0.04 \%)$ наблюдаются в наиболее мористой четвертой пачке сосногорской свиты и в перекрывающих её заведомо морских открыто-шельфовых отложениях ижемской свиты. Карбонатные породы первой и второй пачек сосногорской свиты обеднены $\mathrm{Sr}$, а третьей - обогащены им. При этом в слое «рыбного доломита» содержания $\mathrm{Sr}$ возрастают до
0.05-0.07\%, достигая максимальных значений (0.07-0.1\%) в перекрывающих его немых доломитах. Таким образом, пониженные содержания стронция в нижней части сосногорской свиты подтверждают наше предположение об опресненности бассейна. Относительно аномальные содержания стронция в доломитах слоя 41 свидетельствуют в пользу гипотезы последующего осолонения бассейна в результате выпаривания.

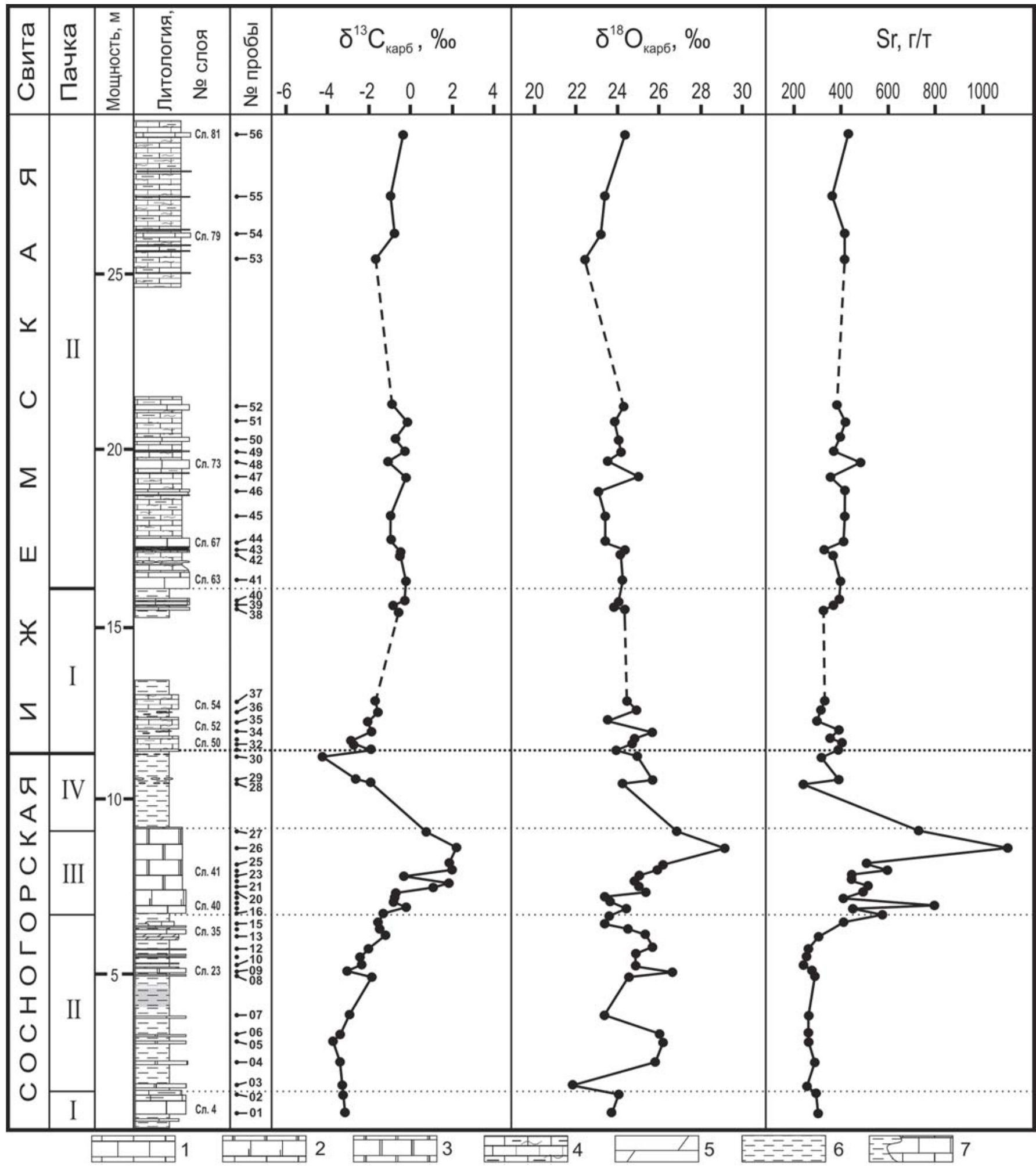

Распределение изотопов карбонатного углерода, кислорода и стронция в разрезе нижнего фамена по р. Ижма (обн. 20). 1 - известняк; 2 - известняк доломитистый; 3 - доломит; 4 - узловатые известняки; 5 - мергель; 6 - глины; 7 - тонкое переслаивание 
Таким образом, в разрезе нижнефаменских отложений по р. Ижма наблюдается четкая коррелятивная связь между тремя проанализированными показателями, а именно: $\delta^{13} \mathrm{C}_{\text {карб }}, \delta^{18} \mathrm{O}_{\text {карб }}$ и $\mathrm{Sr}$. Наиболее резкие синхронные изменения этих показателей как в ту, так и в другую сторону фиксируются в разрезе сосногорской свиты, а в отложениях ижемской свиты их значения почти не меняются. Похожая картина изменения изотопного состава отмечается и в одновозрастных, близких по широте морских разрезах в других регионах мира. Сходство разрезов, выраженное в общем утяжелении изотопного состава карбонатов в интервале конодонтовой зоны triangularis, является, вероятно, отражением глобальных (хотя и кратковременных) трансгрессивных аноксических эпизодов $[6,9]$. Наблюдаемые при этом отличия изученного нами разреза от других по абсолютным значениям упомянутых показателей указывают на то, что отложения сформировались в неодинаковых фациальных обстановках, а следовательно, и в разных палеоэкологических условиях.

Все вышеизложенное позволяет с большой долей уверенности заключить, что формирование отложений типового разреза сосногорской свиты на начальных этапах скорее происходило в прибрежных условиях опресненного водоема озерного типа, нежели в лагуне. Гибель обитавшего здесь сообщества позвоночных, обильные скопления остатков которых наблюдаются в слое 40, была, вероятно, вызвана особенностями самого водоема, а именно - его мелководностью и неоднократной изоляцией, обусловившими в результате резкие изменения физико-химических и биологических параметров его среды. Эти изменения усиливались на фоне ярко выраженной штормовой (ветровой) активности. Связанное со штормами проникновение соленых морских вод и эвтрофикация самого водоема, возникающая в результате перемешивания водной толщи и взмучивания осадка, стали, по-видимому, основными причинами заморов его обитателей и вспышек продуктивности вод бассейна. Те же процессы способствовали быстрому погребению и фоссилизации костных остатков, что в свою очередь позитивно отразилось на степени их нынешней сохранности.

Авторы признательны сотрудникам Института геологии Коми НЦ УрО
РАН Я. Э. Юдовичу и В. С. Чупрову за ценные советы и важные замечания. Работа выполнена в рамках проекта 09-T-5-1028 Программы фундаментальных исследований ОНЗ РАН № 1 и проекта 09-П-5-1012 Программы фундаментальных исследований РАН № 15.

\section{Литература}

1. Безносов П. А. Сосногорская свита - новое местное стратиграфическое подразделение верхнего девона на Южном Тимане // Геология и минеральные ресурсы европейского северо-востока России: Материалы XV Геологического съезда Республики Коми. Т. II. Сыктывкар, 2009. С. 9-12. 2. Безносов П. А., Хипели Д. В., Кузьмин А. В. и др. Литология, остатки позвоночных и конодонты ижемской свиты в стратотипе // Геология и минеральные ресурсы европейского северо-востока России: Материалы XIV Геологического съезда Республики Коми. Т. III. Сыктывкар, 2004. С. 220-224. 3. Кузьмин А. В., Шувалова Г. А., Обуховская Т. Г. u $\partial p$. Пограничные отложения франского и фаменского ярусов ИжмаПечорской впадины // Бюл. МОИП. Отд. геол., 1998. Т. 73. Вып. 4. С. 2738. 4. Москаленко М. Н., Москаленко К. А., Юдина Ю. А. Уточнение биостратиграфического расчленения и корреляции нижнефаменских отложений Ижма-Печорской синеклизы // Геология и минеральные ресурсы европейского северо-востока России: Материалы XIII Геологического съезда Республики Коми. Т. II. Сыктывкар, 1999. С. 224-228. 5. Юдович Я. Э. Проблемы геохимической диагностики фаций седиментогенеза: Материалы к школе-семинару. Томск, 2007. 188 с. 6. Юдович Я. Э., Кетрис $M$. П. Соотношение изотопов углерода в стратисфере и биосфере // Биосфера, 2010. T. 2. № 2. С. 231-246. 7. Ahlberg P. E., Beznosov P. A., Luksevics E. \& Clack J.A. A primitive Devonian tetrapod from the Lower Famennian of South Timan, Russia // Abstracts of The Third International Paleontological Congress. London, 2010. P. 66. 8. Buggisch W. \& Joachimski M. Carbon isotope stratigraphy of the Devonian of Central and Southern Europe // Palaeogeogr., Palaeoclimatol., Palaeoecol., 2006. Vol. 206. P. 68-88. 9. Godderis Y. \& Joachimski M. M. Global change in the Late Devonian: Modeling the FrasnianFamennian short-term carbon isotope excursions // Palaeogeogr., Palaeoclimatol., Palaeoecol., 2004. Vol. 202.
P. 309-329. 10. Hayes J. M., Strauss $H$. $\&$ Kaufman A. J. The abundance of ${ }^{13} \mathrm{C}$ in marine organic matter and isotopic fractionation in the global biogeochemical cycle of the carbon during the past $800 \mathrm{Ma} / /$ Chemical Geology, 1999. Vol. 161, P. 103-125. 11. Holser W. T. Geochemical events documented in inorganic carbon isotope // Palaeogeogr., Palaeoclimatol., Palaeoecol., 1997. V. 132. P. 173-182. 12. House M. R., Menner V. V., Becker R. T. et al. Reef episodes, anoxia and sea-level changes in the Frasnian of the southern Timan (NE Russian platform) // Carbonate Platform Systems: components and interactions / Eds E. Insalaco, P. W. Skelton \& T. J. Palmer (Geological Society of London, Spec. Publ. 178). London, 2000. P. 147176. 13. Joachimski M., Pancost R., Freeman $K$. et al. Carbon isotope geochemistry of the Frasnian Famennian transition // Palaeogeogr., Palaeoclimatol., Palaeoecol., 2002. Vol. 181. P. 91-109. 14. Joachimski M., van Geldern R., Breisig $S$. et al. Oxygen isotope evolution of biogenic calcite and apatite during the Middle and Late Devonian // Int. J. Earth Sci. (Geol. Rundsch.), 2004. Vol. 93. P. 542-553. 15. Kaufman A.J. \& Knoll A. H. Neoproterozoic variations in the $\mathrm{C}$-isotopic composition of seawater: stratigraphic and biogeochemical implications // Prec. Res., 1995. Vol. 73. P. 27-49. 16. Knoll A. H., Hayes J. M., Kaufman A. J. et al. Secular variation in carbon isotope ratios from upper Proterozoic successions of Svalbard and east Greenland // Nature, 1986. Vol. 321. P. 832-838. 17. Kump L. R. \& Arthur $M$. A. Interpreting carbon-isotope excursions: carbonates and organic matter // Chem. Geol., 1999. Vol. 161. P. 181-198. 18. Odum H. T. Strontium in natural waters // Inst. Marine Sci. Pub., 1957. Vol. 4. P. 22-37. 19. Odum H. T. Biogeochemical deposition of strontium // Inst. Marine Sci. Pub., 1957. Vol. 4. P. 38-114. 20. Schindler E. Die Kellwasser-Krise (hohe FrasneStufe, Ober-Devon) / Göttingen Arb. Geol. Paläontol., 1990. Hr. 46. S. 1115. 21. Van Geldern R., Joachimski M. M., Day J. et al. Carbon, oxygen and strontium isotope records of Devonian brachiopod shell calcite // Palaeogeogr., Palaeoclimatol., Palaeoecol., 2006. Vol. 240. P. 47-67. 22. Veizer J., Holser W. T. \& Wilgus C.K. Correlation of ${ }^{13} \mathrm{C} /{ }^{12} \mathrm{C}$ and ${ }^{34} \mathrm{~S} /{ }^{32} \mathrm{~S}$ secular variations // Geochim., Cosmochim. Acta, 1980. Vol. 44. P. 579-587.

Рецензент д. г.-м. н. Я. Э. Юдович 